\title{
The impacts of biofuel crops on local biodiversity: a global synthesis
}

\author{
Sophie Jane Tudge ${ }^{1}$ (D) Andy Purvis ${ }^{1,2}$ (D) $\cdot$ Adriana De Palma ${ }^{2}$ (D)
}

Received: 19 January 2021 / Revised: 27 June 2021 / Accepted: 28 June 2021 /

Published online: 24 July 2021

(C) The Author(s) 2021

\begin{abstract}
Concerns about the impacts of climate change have led to increased targets for biofuel in the global energy market. First-generation biofuel crops contain oil, sugar or starch and are usually also grown for food, whereas second-generation biofuel is derived from nonfood sources, including lignocellulosic crops, fast-growing trees, crop residues and waste. Biofuel production drives land-use change, a major cause of biodiversity loss, but there is limited knowledge of how different biofuel crops affect local biodiversity. Therefore, a more detailed understanding could inform more environmentally-conscious decisions about where to grow which biofuel crops. We synthesised data from 116 sources where a potential biofuel crop was grown and estimated how two measures of local biodiversity, species richness and total abundance, responded to different crops. Local species richness and abundance were $37 \%$ and $49 \%$ lower at sites planted with first-generation biofuel crops than in sites with primary vegetation. Soybean, wheat, maize and oil palm had the worst effects; the worst affected regions were Asia and Central and South America; and plant species richness and vertebrate abundance were the worst affected biodiversity measures. Second-generation biofuels had smaller, but still significant, effects: species richness and abundance were $19 \%$ and $25 \%$, respectively, lower in such sites than in primary vegetation. Our models suggest that land clearance to cultivate biofuel crops reduces local biodiversity. However, the yield of biofuel from different crops influences the biodiversity impacts per unit of energy generated, and the geographic and taxonomic variation in effects are also relevant for making sustainable land-use decisions.
\end{abstract}

Keywords Land-use change $\cdot$ Agriculture $\cdot$ Biodiversity loss $\cdot$ Biofuels $\cdot$ Energy $\cdot$ Yield

Communicated by Anurag chaurasia.

Adriana De Palma

a.de-palma@nhm.ac.uk

1 Department of Life Science, Imperial College London, Ascot, UK

2 Department of Life Sciences, Natural History Museum, London, UK 


\section{Introduction}

Global biodiversity is continuing to decline, with an increasing number of species at risk of extinction (Tittensor et al. 2014; Díaz et al. 2019). Land-use change is currently the biggest threat to biodiversity, followed by overexploitation, climate change and invasive species, and these threats are worsening (Butchart et al. 2010; Díaz et al. 2019). Land-use change is driven predominantly by agricultural expansion and intensification, with agricultural activities now occupying approximately $38 \%$ of the ice-free terrestrial surface (Ramankutty et al. 2008). Demand for agricultural products is likely to rise further given the projected increase in human population, heightening the pressure on land and biodiversity in the future (Godfray et al. 2010; United Nations 2019).

While land-use change is currently the major direct threat to terrestrial biodiversity (Díaz et al. 2019), it needs to be balanced with other environmental concerns, including climate change (Thomas et al. 2004). One way of tackling climate change is by increasing the proportion of cleaner, renewable energy sources in the global energy mix (International Energy Agency 2014). Biofuels (derived from plant material) are one such renewable energy source that are considered a good alternative to fossil fuels due to their potentially lower carbon emissions (Thuiller 2007). However, despite being seen as a clean energy source there are both benefits and drawbacks of using biofuel on a global scale (Arodudu et al. 2020). For example, it is thought that trading biomass could increase energy security by reducing dependence on finite petroleum resources (Ragauskas et al. 2006) and provide new income for farmers in the developing world (Mathews 2007). However, biofuel use can lead to increased demand for water and fertiliser (Beringer et al. 2011) and higher carbon emissions than fossil fuels if land is deforested in order to grow biofuel crops (Danielsen et al. 2009; Tilman et al. 2009; Dornburg et al. 2010). Nevertheless, private investment in biofuels has been encouraged by governments worldwide, and by 2012 biofuels met $10 \%$ of global energy demand; this demand is likely to triple by 2040 (International Energy Agency 2014), growing particularly quickly in developing countries (Gadonneix et al. 2010).

The market for biofuels consists mainly of bioethanol and biodiesel. These can be produced from food or non-food crops, raising additional concerns about competition with food production (Immerzeel et al. 2014). Biofuels derived from food crops and vegetable oils, such as maize and palm oil, are classified as first-generation (Correa et al. 2017). Firstgeneration crops make up most of the global biofuel supply, and are also some of the most intensively farmed crops worldwide, associated with large-scale environmental destruction (Dornburg et al. 2010; Correa et al. 2017). Second-generation biofuels are mainly derived from perennial crops that are not grown for food, including lignocellulosic crops and fastgrowing trees, which have lower yields (Dauber et al. 2010). Second-generation biofuels can also be derived from the non-edible parts of food crops (Szymanska-Chargot et al. 2017), from forestry waste and from municipal waste (Koh and Ghazoul 2008). Additional sources of biofuel exist, such as microalgae and some microbes, that are sometimes considered third-generation (Groom et al. 2008; Leite et al. 2013).

Palm oil is among the best-known first-generation biofuels. It is the main source of vegetable oil and a major source of biodiesel (Fitzherbert et al. 2008), but expansion of oil palm plantations has already led to large-scale land clearance and deforestation, particularly in Southeast Asia (Dornburg et al. 2010; Barnes et al. 2014). In Malaysia and Indonesia, over half of the expansion between 1990 and 2005 occurred at the expense of forest habitat (Koh and Ghazoul 2008), resulting in significant ecological changes. The 
uniform structure of plantations compared to natural forest reduces the species diversity and leads to the dominance of generalist species at the expense of specialists, which tend to be of greater conservation concern (Fitzherbert et al. 2008; Phillips et al. 2017). Reduced species richness in oil palm plantations has been reported for a variety of taxa, including birds (Aratrakorn et al. 2006; Peh et al. 2006), bats (Freudmann et al. 2015), invertebrates (Barnes et al. 2014), plants and lizards (Danielsen et al. 2009).

Whereas oil palm is the dominant biofuel crop in Southeast Asia, the USA and Brazil together produce around $80 \%$ of global biofuel in the form of bioethanol from maize and sugarcane, respectively (Gadonneix et al. 2010). Row crops such as maize are more efficient when grown in large monocultures (Wiens et al. 2011), accompanied by the removal of natural features, such as copses, to produce landscapes with reduced compositional and configurational heterogeneity (Fahrig et al. 2011). The modified landscape affects the availability of resources and the movement and abundance of species (Flather and Bevers 2002; Fahrig et al. 2011). Research into row crops, and other first-generation biofuel crops including oil palm, has found particular declines in vertebrates (Fitzherbert et al. 2008; Fletcher et al. 2011). For example, bird diversity and mammal abundance were found to be over 50\% lower in row crop fields in the USA compared to non-crop areas (Fletcher et al. 2011). Intensively managed croplands in the USA and Europe also affect pollinator communities, leading to a reduced species richness and abundance of bees (Kennedy et al. 2013; Koh et al. 2016).

Because first-generation biofuels are generally higher-yielding than second-generation biofuels, they are thought to be more damaging to biodiversity, per unit area (Immerzeel et al. 2014; Núñez-Regueiro et al. 2020), and studies have reported that second-generation biofuels can have positive effects on aspects of biodiversity in temperate regions. For example, perennial grasses and short rotation coppiced willow have been found to diversify local vegetation structure and increase invertebrate abundance, which can provide food for birds and enhance avian diversity (Robertson et al. 2011; Haughton et al. 2016). These benefits may relate to several factors, including reduced chemical inputs, longer rotation periods and greater spatial heterogeneity (Dauber et al. 2010). Biodiversity benefits have been found for second-generation woody and herbaceous crops including poplar, willow (Vanbeveren and Ceulemans 2019) and perennial grasses (Robertson et al. 2011; Kline et al. 2015; Haughton et al. 2016) when compared to annual row crops. Second-generation crops can also be grown on a wider range of land types including marginal or degraded land, which would not otherwise be suitable for food crops (Wiens et al. 2011), thus providing bioenergy without the need for further land clearance (Immerzeel et al. 2014) or additional competition with food production (Erb et al. 2012).

Previous studies that have considered regional differences have shown that Asia's biodiversity is affected more strongly by land-use change (Gibson et al. 2011) and conversion to plantations (Phillips et al. 2017) than other regions. The reasons probably relate to the intrinsic sensitivities of the species present and differences in the sampling techniques used, crops grown and local management practices (Gibson et al. 2011; Phillips et al. 2017). Existing comparisons between oil palm plantations (predominant in Asia) and other crops, do indeed highlight oil palm's particularly detrimental effects. For example, analyses have found lower species richness in oil palm plantations than in second-generation wood, fruit, vegetable, coffee, cocoa and rubber plantations (Peh et al. 2006; Fitzherbert et al. 2008; Barnes et al. 2014; Phillips et al. 2017).

With such a diverse range of crops available for biofuel production and more land continuously being converted to cropland, there is a growing need to be able to predict how ecological communities around the world could be affected by different biofuels. 
Integrating this knowledge into sustainability assessments can help to guide land-use decisions by highlighting locations around the world where certain biofuel crops could be grown with the least damage to biodiversity. However, most studies on biofuels and biodiversity are limited in taxonomic scope and are restricted to particular tropical or temperate regions (Dauber et al. 2010; Dornburg et al. 2010; Dauber and Miyake 2016). These limitations are problematic given that biodiversity impacts can vary among regions and taxonomic groups (Phillips et al. 2017; Núñez-Regueiro et al. 2020), and that long-distance biofuel trade poses a particular challenge to sustainability (Araújo et al. 2017). Synthesising studies from multiple geographic regions that investigate how a wide range of taxonomic groups are impacted by a variety of biofuel crops provides the best prospect for understanding some of these context-dependencies of the biofuel-biodiversity relationship, and for providing results that are robust enough to inform conservation and policy.

In this paper, we have made use of the interrelatedness between food and biofuel crops to analyse the biodiversity response to crops using data from published studies that have been collated within the PREDICTS database (Projecting Responses of Ecological Diversity In Changing Terrestrial Systems). The database provides a framework for modelling how site-level biodiversity responds to different land-uses and related pressures, and contains information on the biodiversity in croplands around the world (Hudson et al. 2014, 2017). We focused our analyses on the biodiversity impacts of first- and second-generation biofuels and compared the effects of 62 biofuel crops in different geographic regions and on different taxonomic groups.

\section{Methods}

\section{Identifying biofuels in the PREDICTS database}

The PREDICTS database (Hudson et al. 2017) contains data from published articles, or reports using published methods, on biodiversity in sites with contrasting land-uses and human pressures around the world. Our research used pre-existing data that had been collated into the database by the project team between March 2012 and March 2018, using the methods described in Hudson et al. (2017) and following extensive literature searches. Although no data were added specifically for the purpose of this research, we compiled a new, complementary database that, for each of the crops grown in sites included in the PREDICTS database, assessed whether that crop could be used as a first- or second-generation biofuel. Within the PREDICTS database, each source comprises one or more studies (each with a different sampling methodology), which may be arranged in spatial blocks, and that each have data from two or more sites where species richness, abundance or occurrence have been measured using the same procedure, with detail on sampling effort and geographic coordinates (see Hudson et al. 2014 for details).

Each site within the database is assigned a land-use, which can be cropland, pasture, plantation forest, primary forest or non-forest, secondary vegetation (of different ages) or urban (Hudson et al. 2014). Sites are also assigned a coarse land-use intensity-minimal use, light use, intense use or cannot decide-based on the authors' descriptions of the level of use of the sites by humans (Hudson et al. 2014). For cropland sites, minimal use tends to mean small farms with mixed crops and little to no additional inputs, like fertilisers or pesticides. Lightly used croplands tend to be medium-intensity farms that could be larger, have more chemical inputs and be mechanised. Intensively used croplands are monoculture 
farms that could have larger fields, more chemical inputs, no crop rotation and annual ploughing, amongst other things. The land-use intensity descriptions for each land-use are reproduced from Hudson et al. (2014) in Online Resource 1.

For our analyses we combined all primary sites into one class and all secondary vegetation sites into another, and extracted from the database the sites where the predominant habitat was cropland or plantation forest and where the name of the crop grown was known, using site-specific crop data from Hill et al. (2018). We then conducted a literature search of the crops to find out which can be used as biofuels, using the scientific or common crop name and a variety of biofuel terms, including biofuel, biodiesel, bioethanol, ethanol, fuel, energy and bioenergy. When the crop name was too broad, such as the family name Poaceae, it was excluded from the search, as it was not possible to tell which species or subspecies were grown at the site. However, some genus names were included when it was still possible to assess their suitability, such as wheat. We classified each biofuel crop as first- or second-generation (Table 1) and into categories of similar crops. In some instances, the crop category contained a single species, e.g. oil palm, but in other instances, where individual crops were not grown at many sites and the biodiversity impacts of similar crops were hypothesised to be similar, the category contained a group of crops e.g. the fruit/vegetable and perennial grass categories. The crop categories containing multiple species also tended to contain less widely used biofuel crops. First-generation biofuel crops had the highest proportion of sites where land-use was classified as intensively managed within the database, rather than light, minimal or unknown intensity of use ( $48 \%$ for firstgeneration crops compared to $16 \%$ for second-generation crops) (Table 2). Because our main focus was the differences between, rather than within, biofuel generations and categories, we did not use land-use intensity as an explanatory variable, but interpreted our results assuming that sites with first-generation biofuels tend to be more intensively managed than sites with second-generation biofuels.

Very few sources explicitly stated whether crops at each site were being grown for biofuel (only three out of 120 sources that were checked mentioned a biofuel term anywhere in the article). We therefore treated all sites with biofuel crops as biofuel sites, as in Fletcher et al. (2011) and Núñez-Regueiro et al. (2020), assuming that the biodiversity effects of growing the crop do not much depend on the crop's end use. Analysis of data from sites that are actually being used for biofuel would be preferable, and may produce

Table 1 Criteria for sites within the PREDICTS database to be classed as first-generation biofuel or second-generation biofuel for our analyses

\begin{tabular}{|c|c|}
\hline Biofuel generation & Inclusion criteria \\
\hline First & $\begin{array}{l}\text { Site has a single first- } \\
\text { generation biofuel } \\
\text { crop } \\
\text { Site has more than one } \\
\text { biofuel crop, all of } \\
\text { which are first-gen- } \\
\text { eration }\end{array}$ \\
\hline Second & $\begin{array}{l}\text { Site has a single } \\
\text { second-generation } \\
\text { biofuel crop } \\
\text { Site has more than one } \\
\text { biofuel crop, all of } \\
\text { which are second- } \\
\text { generation }\end{array}$ \\
\hline
\end{tabular}


Table 2 Land-use intensity for each site from the PREDICTS database that was used for our analyses, based on the authors' descriptions of how heavily used the sites are by humans

\begin{tabular}{lcccc}
\hline Land-use & \multicolumn{4}{l}{ Number of sites with each land-use intensity } \\
\cline { 2 - 5 } & Cannot decide & Intense use & Light use & Minimal use \\
\hline First-generation biofuel & 41 & 258 & 220 & 24 \\
Second-generation biofuel & 106 & 138 & 335 & 282 \\
Primary vegetation & 464 & 617 & 2556 & 5204 \\
Secondary vegetation & 1452 & 723 & 1804 & 3196 \\
Pasture & 1091 & 1476 & 2305 & 1609 \\
Urban & 41 & 287 & 756 & 401 \\
\hline
\end{tabular}

Sites can fall into one of three coarse land-use intensity categories (intense, light or minimal), or the "cannot decide' category if there is insufficient information. The land-use intensity descriptions are reproduced from Hudson et al. (2014) in Online Resource 1

different results, however there are currently sparse data on biodiversity in croplands where the crop is explicitly used for biofuel.

\section{Statistical modelling}

We modelled the response of biodiversity to biofuel crop generation and biofuel crop type (using our biofuel crop category grouping), comparing the results with the other PREDICTS land-uses (primary vegetation, secondary vegetation, pasture and urban) (Hudson et al. 2014). As measures of local biodiversity, we used species richness and total abundance. Although other biodiversity measures that reflect species composition and the relative abundances of the species present contain more information and are more sensitive to biodiversity change (Santini et al. 2016; Hillebrand et al. 2018), most papers only report a single measure of biodiversity, most commonly species richness (Naeem et al. 2016). We tested whether the effects of first- and second-generation biofuel crops differed significantly among geographic regions (Africa, Asia, Europe, Central and South America, North America and Oceania) and major taxonomic groupings (plants, vertebrates and invertebrates). Thus, in all, we fitted eight models: two to describe the overall effects of biofuel crop generation on species richness and total abundance, two for the effects of biofuel crop category on species richness and total abundance, two for the effects of biofuel crop generation in different regions on species richness and total abundance, and two for the effects of biofuel crop generation on species richness and total abundance for different taxonomic groups. These were all fitted as linear mixed-effects models using the "lme4" package (Bates et al. 2015), as such models are suitable when dealing with a nested data structure (e.g. there are differences in sampling methods and sampling effort between studies) (Phillips et al. 2017; Núñez-Regueiro et al. 2020). The mixed-effects models were able to account for the non-independence of biodiversity measures within studies (SS: sourcestudy) and blocks (SSB: source-study-block) by fitting them as random intercepts.

Species richness models were fitted with a Poisson error structure and a log link function (Zuur et al. 2009); to deal with overdispersion otherwise seen in these models, a site level random intercept was included (SSBS: source-study-block-site) (Newbold et al. 2015). Total abundance is not always an integer, so a Poisson error structure could not be used; instead, data were $\log (\mathrm{x}+1)$ transformed and modelled with a Gaussian error structure. 
For each of the eight models, we first compared different random intercept structures and chose the structure with the lowest Akaike Information Criterion. We did not include random slopes to increase the chance of model convergence. To choose the best fixed-effects structure we used backwards stepwise model simplification of fixed effects using likelihood ratio tests (Zuur et al. 2009). The fixed effects that were considered included the interactions between biofuel generation and region and between biofuel generation and taxon, but we did not include three-way interactions.

When a model failed to converge, we increased the number of iterations and then used the "allFit()" function from the "Ime4" package to compare the estimated values from all available different optimizers. If all optimizers gave very similar estimates (within 0.01), we considered the convergence warnings to be false positives (Bates et al. 2015). We also used the "MCMCglmm" package and compared the outputs, verifying that values were within 0.01 of each other (Hadfield 2010).

For the final models, the "MuMIn" package was used to calculate the marginal $\mathrm{R}^{2}$ (amount of variance explained by fixed factors) and the conditional $\mathrm{R}^{2}$ (amount of variance explained by fixed and random factors) (Bartoń 2018). Additionally, the "car" package was used to conduct type II anova tests on the models (Fox and Weisberg 2011). All analyses were carried out using R version 3.4.2 (R Core Team 2017).

\section{Results}

\section{Biofuels in the PREDICTS database}

At the time of our analyses, the PREDICTS database contained data from 32,076 sites and 552 sources. At least one crop name was available from 4,033 sites (159 sources), giving a total of 150 names, although some were different spellings of the same crop. Excluding those where the names were too vague, we assessed 95 unique crops for biofuel potential. Of the 95 crops, we found research identifying 65\% (62 crops) as a biofuel by at least one source, with the majority (49) of the crops having waste that could be used for biofuel. Online Resource 2 gives detail of our assessment of the crops' biofuel potential and grouping into biofuel generations and categories. Of the biofuel crops identified, 26 were first-generation and 36 were second-generation. We grouped the biofuel sites into the following categories, to enable robust statistical modelling: coffee, cotton, fruit/vegetable, maize, mixed crops, oil palm, other grain, other oil crop, perennial grass, rapeseed oil, rubber, soybean and wheat. There were not enough data (only three sites) to include woody crops in our analysis of the effects of biofuel category on biodiversity. Our dataset included 543 first-generation biofuel sites and 861 second-generation biofuel sites. The geographic spread of data was uneven, with the majority of first-generation sites in Europe and secondgeneration sites in Central and South America. Due to imbalance in the variety of crops grown in each region and the taxonomic groups recorded in each crop category, we did not model the effects of individual crop categories in different regions or on different taxonomic groups separately (see Online Resource 3).

\section{Biofuels and biodiversity}

Biofuel crop generation had a significant effect on the total abundance $\left(\chi^{2}=118.21, \mathrm{df}=5\right.$, $\mathrm{p}<0.001)$ and species richness $\left(\chi^{2}=443.39, \mathrm{df}=5, \mathrm{p}<0.001\right)$ of sites. Overall, species 
richness was $37 \%$ lower (estimate $=-0.45, \mathrm{SE}=0.03, \mathrm{p}<0.001$; Fig. 1 ) and total abundance $39 \%$ lower (estimate $=-0.49, \mathrm{SE}=0.07, \mathrm{t}=-7.15$; Fig. 2 ) in first-generation biofuel sites than in primary vegetation, which were the biggest declines of all the land-uses assessed. Second-generation biofuel sites had a total abundance 25\% (estimate $=-0.29, \mathrm{SE}=0.06$, $\mathrm{t}=-5$.2) lower than primary vegetation, which was lower than pasture, secondary vegetation and urban sites.

The type of biofuel crop (category) also had a significant effect on total abundance $\left(\chi^{2}=313.21, \mathrm{df}=16, \mathrm{p}<0.001\right)$ and species richness $\left(\chi^{2}=518.32, \mathrm{df}=16, \mathrm{p}<0.001\right)$. Sites where cotton and soybean were grown recorded the lowest species richness, followed by wheat and maize (Fig. 3). Species richness in sites with other grain crops and rubber was not significantly different from that in primary vegetation (although the confidence intervals were wide), whereas all other crop categories had a significantly lower species richness. Sites with cotton also had a very low total abundance of organisms (86\% less than primary vegetation), followed by soybean and oil palm. On the other hand, abundance in sites planted with rubber, other oil crops and fruit/vegetable did not differ significantly from that in primary vegetation, and perennial grass and rapeseed oil crops had total abundances more than $50 \%$ higher (Fig. 4).

\section{Geographic variation}

The effects of the two generations of biofuel crops on biodiversity varied significantly among regions (Table 3). From our data, sites with first-generation biofuels supported fewer species on average than sites with second-generation biofuels for all regions (Fig. 5). Within the first-generation group, all regions had significantly lower species

Fig. 1 Species richness in sites with first- and second-generation biofuel crops and reference land-uses from the PREDICTS database: primary vegetation, secondary vegetation, pasture and urban. Error bars show 95\% confidence intervals. Error bars that do not cross zero are considered significantly different to the baseline, primary vegetation. Data point labels show sample size i.e. number of sites

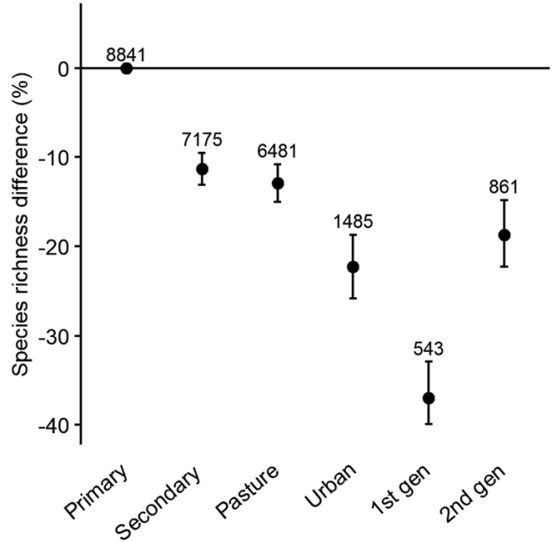

richness than primary vegetation (apart from North America, which showed wide variability), between $40 \%$ lower in Asia and $31 \%$ lower in Europe. In our model of croplands with second-generation biofuels, species richness was significantly lower than primary vegetation only in Africa, Asia and Central and South America.

First-generation biofuel sites also had a lower total abundance of organisms than second-generation sites in all regions except for Africa, where abundance was lowest in second-generation sites. First-generation biofuels grown in Central and South America 
Fig. 2 Total abundance in sites with first- and second-generation biofuel crops and reference land-uses from the PREDICTS database: primary vegetation, secondary vegetation, pasture and urban. Error bars show 95\% confidence intervals. Error bars that do not cross zero are considered significantly different to the baseline, primary vegetation. Data point labels show sample size i.e. number of sites

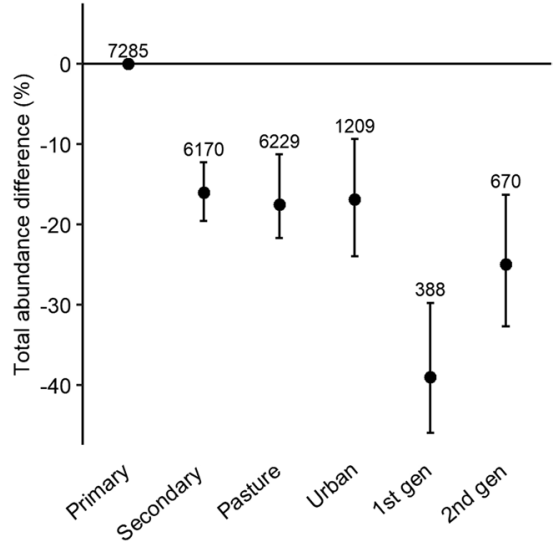

and Asia had the biggest impact on total abundance across all the regions, according to our model (Fig. 6). In Europe, all land-uses supported lower total abundance than primary vegetation. On the other hand, in North America only pasture had a lower total abundance than primary vegetation, and second-generation biofuels increased it by $138 \%$ (however, there were very large confidence intervals). Similarly, in Oceania, we found that biofuels had no significant effect on total abundance.

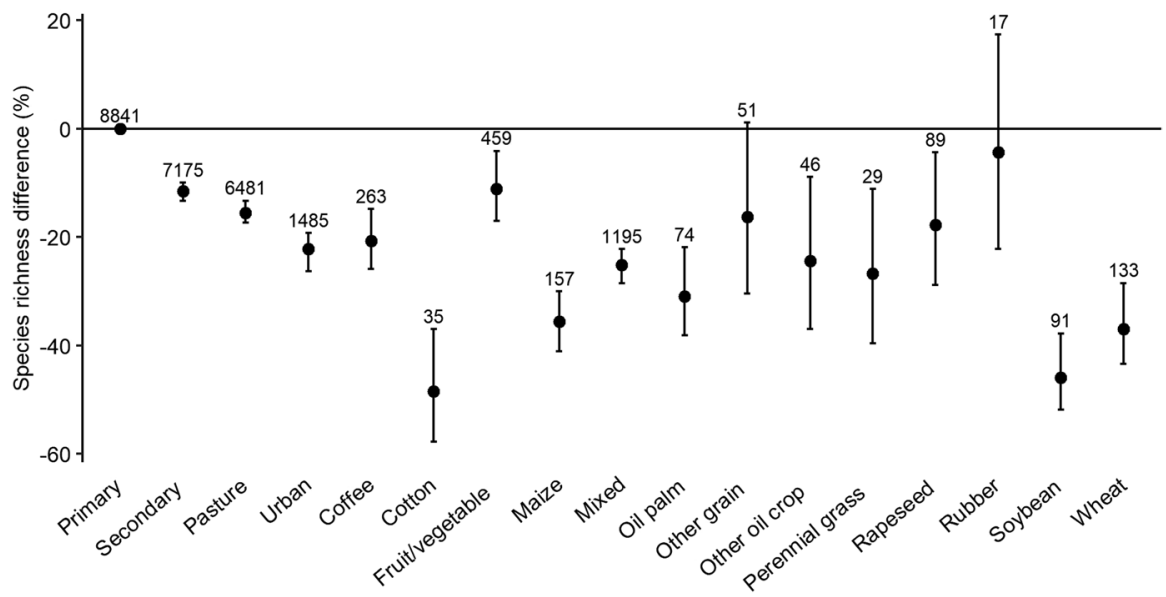

Fig. 3 Species richness in biofuel crop categories and reference land-uses from the PREDICTS database: primary vegetation, secondary vegetation, pasture and urban. Error bars show 95\% confidence intervals. Error bars that do not cross zero are considered significantly different to the baseline, primary vegetation. Data point labels show sample size i.e. number of sites 


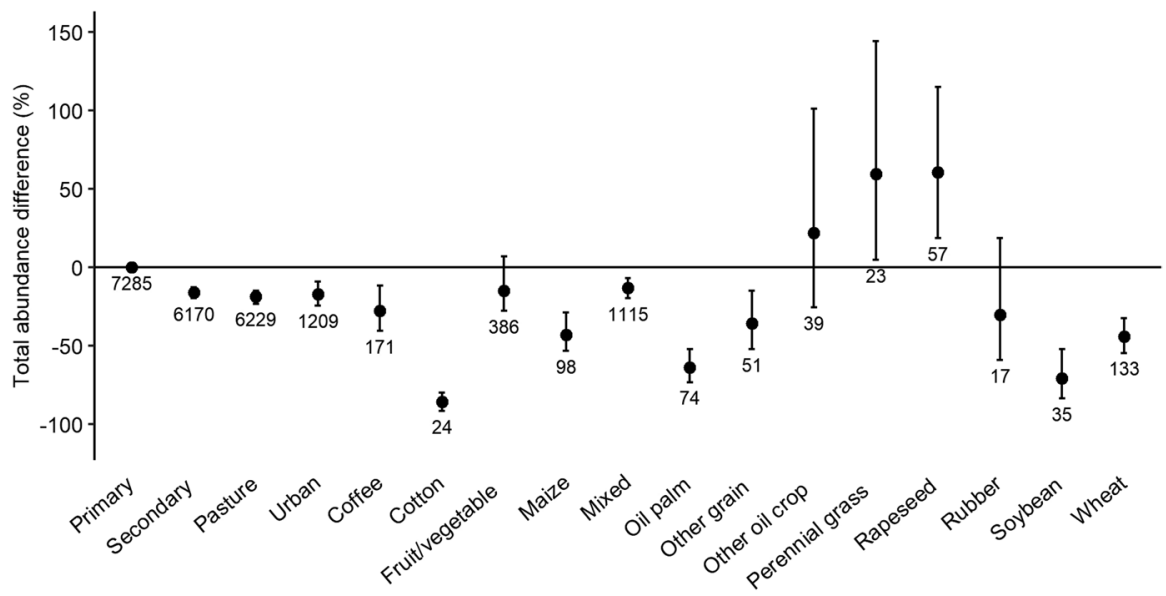

Fig. 4 Total abundance in biofuel crop categories and reference land-uses from the PREDICTS database: primary vegetation, secondary vegetation, pasture and urban. Error bars show $95 \%$ confidence intervals. Error bars that do not cross zero are considered significantly different to the baseline, primary vegetation. Data point labels show sample size i.e. number of sites

Table 3 Type II anova results for minimum adequate models with total abundance and species richness as the response variables and land-use (including biofuel generation), region and their interaction as the explanatory variables

\begin{tabular}{lllllll}
\hline Model response variable & Model explanatory variable & Df & logLik & Chisq & Chi Df & Pr $(>$ Chisq) \\
\hline Total abundance & Land-use only & 9 & $-28,432$ & & & \\
& Land-use + Region & 14 & $-28,427$ & 10.55 & 5 & 0.06 \\
& Land-use * Region & 39 & $-28,233$ & 387.54 & 25 & $<0.001$ \\
Species richness & Land-use only & 9 & $-72,425$ & & & \\
& Land-use + Region & 14 & $-72,419$ & 11.40 & 5 & 0.04 \\
& Land-use * Region & 39 & $-72,287$ & 263.68 & 25 & $<0.001$ \\
\hline
\end{tabular}

Chisq is the result of a chi-square test, Df is degrees of freedom and logLik is log-likelihood. $\operatorname{Pr}(>$ Chisq) is a measure of the significance of the model explanatory variable shown

\section{Taxonomic variation}

The interaction between taxonomic group and biofuel generation was significant for both species richness and total abundance (Table 4). Croplands with first-generation biofuels had lower species richness of vertebrates (by 28\%), invertebrates (by 31\%) and plants (by 49\%) than did primary vegetation (Fig. 7). First-generation sites showed a lower species richness than second-generation sites for all taxa, and for invertebrates and plants this was the lowest value of all the land-uses. The total abundance of plants was not significantly affected by first-generation biofuels, but was $46 \%$ lower in second-generation sites (Fig. 8). However, the site-level total abundance of vertebrates and invertebrates was significantly lower in both generations of biofuel, and lower in first- than second-generation sites. The worst effect of biofuels, and indeed any 

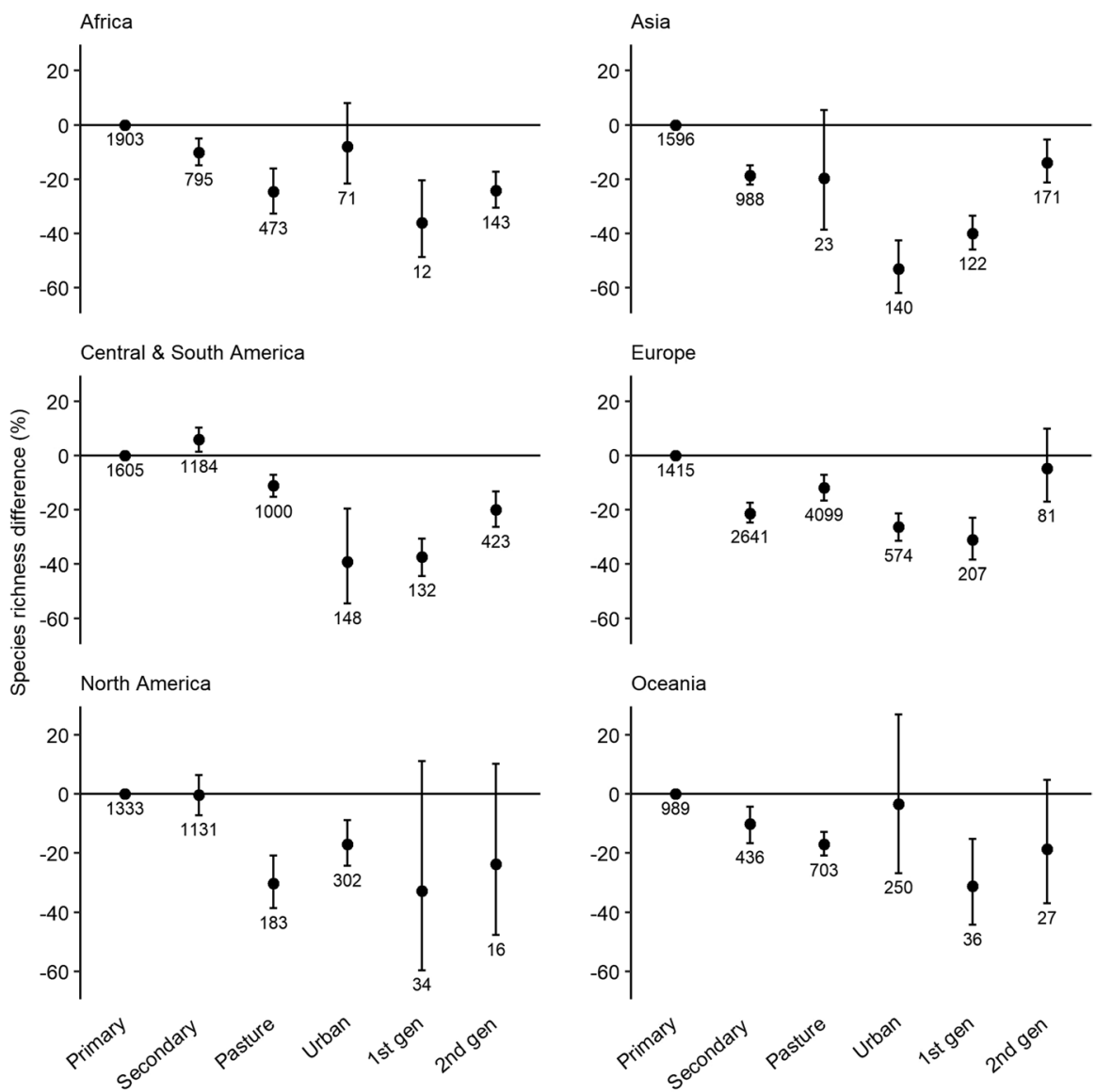

Fig. 5 Species richness in sites with first- and second-generation biofuel crops and reference land-uses from the PREDICTS database: primary vegetation, secondary vegetation, pasture and urban, in Africa, Asia, Central and South America, Europe, North America and Oceania. Error bars show 95\% confidence intervals. Error bars that do not cross zero are considered significantly different to the baseline, primary vegetation. Data point labels show sample size i.e. number of sites

land-use, was on the abundance of vertebrates in first-generation sites, which was $69 \%$ lower than in primary vegetation. The only positive effect of land-use on biodiversity in these analyses came from the abundance of vertebrates in urban environments.

For the eight final model outputs, see Online Resources 4-11.

\section{Discussion}

We conducted a global synthesis exploring the impacts of biofuel crops on local biodiversity, comparing the largest range of biofuel crops and potential biofuel crops to date (Immerzeel et al. 2014; Núñez-Regueiro et al. 2020). All of the crops in our analyses were damaging to at least one aspect of biodiversity, therefore our results corroborate previous findings that biofuel crops are damaging to biodiversity (Robertson et al. 2011; Immerzeel 

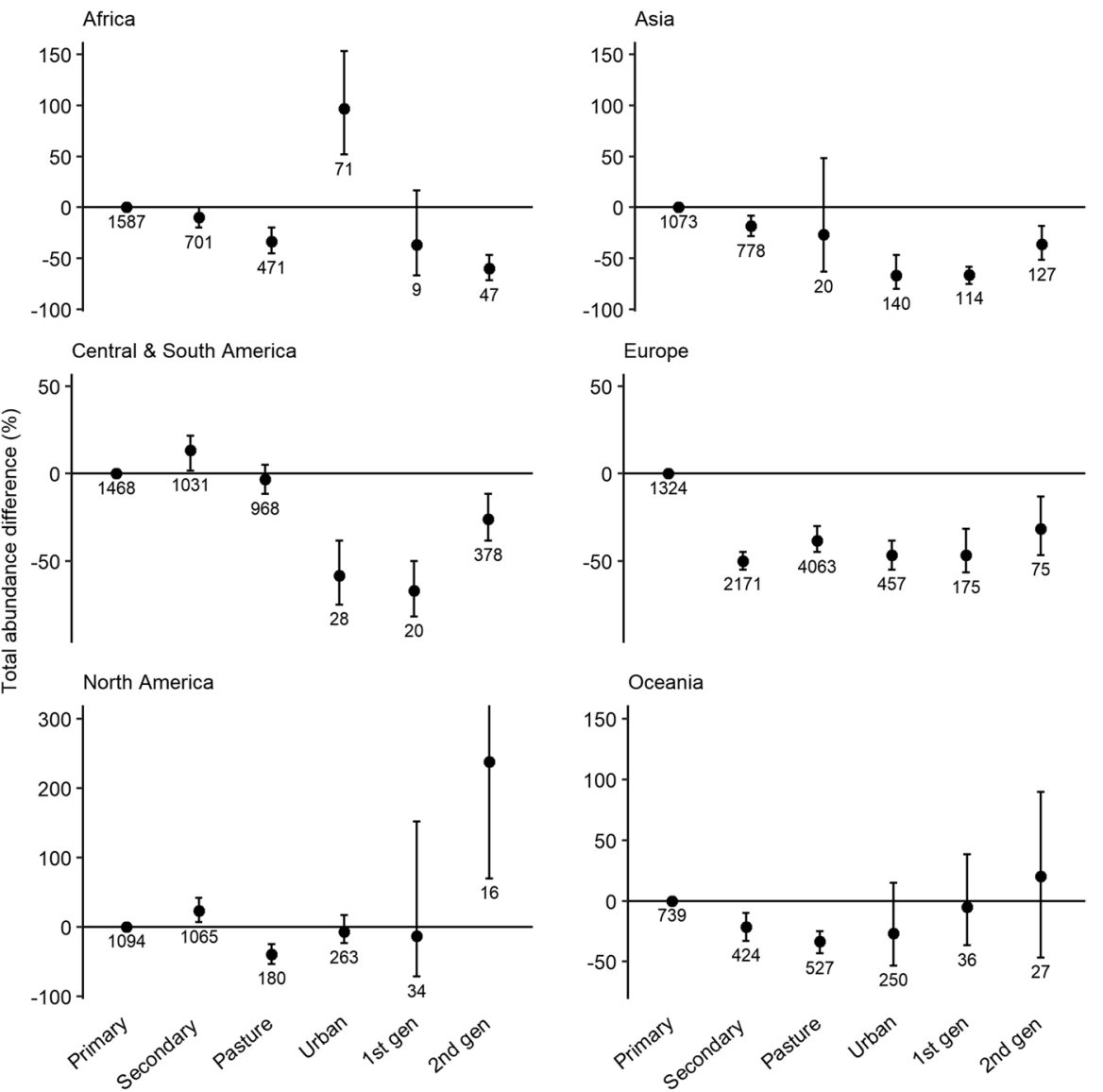

Fig. 6 Total abundance in sites with first- and second-generation biofuel crops and reference land-uses from the PREDICTS database: primary vegetation, secondary vegetation, pasture and urban, in Africa, Asia, Central and South America, Europe, North America and Oceania. Error bars show 95\% confidence intervals. Error bars that do not cross zero are considered significantly different to the baseline, primary vegetation. Data point labels show sample size i.e. number of sites

Table 4 Type II anova results for minimum adequate models with total abundance and species richness as the response variables and land-use (including biofuel generation), taxon and their interaction as the explanatory variables

\begin{tabular}{llrlrrr}
\hline Model response variable & Model explanatory variable & Df & $\log$ Lik & Chisq & Chi Df & Pr $(>$ Chisq) \\
\hline Total abundance & Land-use only & 9 & $-27,979$ & & & \\
& Land-use + Taxon & 11 & $-27,955$ & 47.41 & 2 & $<0.001$ \\
& Land-use * Taxon & 21 & $-27,869$ & 173.40 & 10 & $<0.001$ \\
Species richness & Land-use only & 9 & $-70,844$ & & & \\
& Land-use + Taxon & 11 & $-70,829$ & 29.69 & 2 & $<0.001$ \\
& Land-use * Taxon & 21 & $-70,736$ & 185.75 & 10 & $<0.001$ \\
\hline
\end{tabular}

Chisq is the result of a chi-square test, Df is degrees of freedom and logLik is log-likelihood. Pr ( $>$ Chisq) is a measure of the significance of the model explanatory variable shown 
Fig. 7 Species richness in sites with first- and second-generation biofuel crops and reference land-uses from the PREDICTS database: primary vegetation, secondary vegetation, pasture and urban, for plants, invertebrates and vertebrates. Error bars show $95 \%$ confidence intervals. Error bars that do not cross zero are considered significantly different to the baseline, primary vegetation. Data point labels show sample size i.e. number of sites

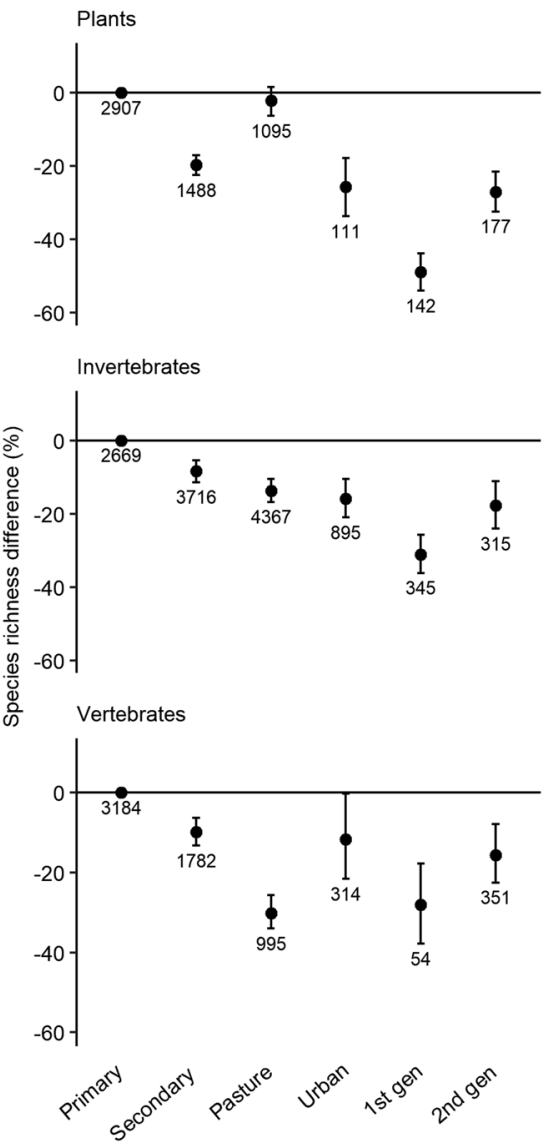

et al. 2014; Haughton et al. 2016; Núñez-Regueiro et al. 2020), whilst providing new insights into the differences globally and regionally. Our results showed that traditional first-generation biofuel crops including soybean, maize and oil palm were the most detrimental to local species richness and total abundance, worse even than urban environments. Although comparatively better, second-generation biofuel crops were also damaging to these measures of biodiversity overall, but with differences between individual crops. The demand for biofuels and the associated land required to grow biofuel crops is likely to increase in the future (International Energy Agency 2014), leading to land-use change and implications for biodiversity. Due to the variation we identified in biodiversity in different biofuel crop systems, and in order to minimise the negative impacts of biofuels on biodiversity, biofuel policies that guide future land-use decisions should be tailored to consider how local biodiversity might respond to particular crops, grown in particular geographic regions. All else being equal, those biofuel crops with the least harmful impacts on local biodiversity should be prioritised over other potential biofuels.

The finding that first-generation biofuels were on average more harmful to local species richness than second-generation biofuels in all regions is not surprising given their higher use-intensity. They tend to be monocultures with significant chemical inputs, no 
Fig. 8 Total abundance in sites with first- and second-generation biofuel crops and reference land-uses from the PREDICTS database: primary vegetation, secondary vegetation, pasture and urban, for plants, invertebrates and vertebrates. Error bars show $95 \%$ confidence intervals. Error bars that do not cross zero are considered significantly different to the baseline, primary vegetation. Data point labels show sample size i.e. number of sites
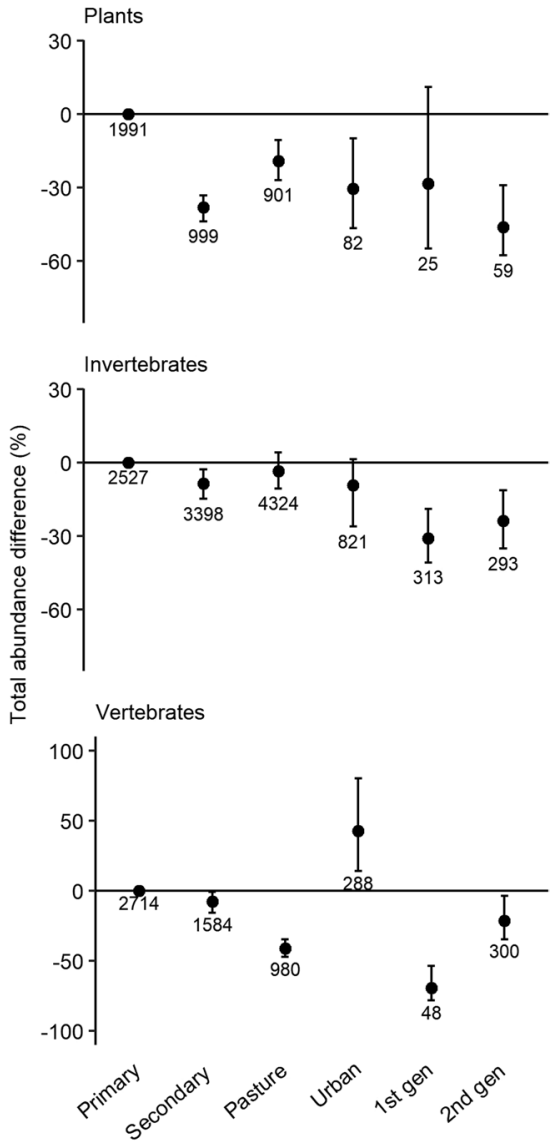

crop rotations, recent clear-felling etc. (Hudson et al. 2014). Many studies have now linked agricultural intensification to a loss of biodiversity, including decreased diversity and abundance of farmland birds and insects, consistent with our results (e.g. Donald et al. 2006; Raven and Wagner 2021). We found that soybean (the most important source of biodiesel in Brazil, one of the world's largest biodiesel producers (Cerri et al. 2017)) severely reduced local biodiversity, more so than other row crops including maize (Fargione et al. 2010; Poggio et al. 2013). Yet maize and wheat were still very damaging compared to primary and secondary vegetation and second-generation biofuels, reflecting the homogeneity and limited resource availability in row crop landscapes (Smith et al. 2010).

In our models, soybean also supported fewer species than oil palm plantations, whereas Fargione et al. (2010) found the opposite to be true, highlighting differences that can arise depending on data sources and study systems. Nonetheless, our results agree with previous studies that oil palm plantations support fewer species than second-generation coffee, fruit/vegetable and rubber plantations (Peh et al. 2006; Fitzherbert et al. 2008; Barnes et al. 2014; Phillips et al. 2017). Analyses of the greenhouse gas emissions arising from the production of biofuels, using life cycle assessment methods, have had varied results, but a recent analysis by Meijide et al. (2020) found that biofuel generated from young oil 
palm plantations releases more greenhouse gas emissions than fossil fuels, with consideration given to soil emissions and emissions during the cultivation, milling and fuel production stages. Therefore, oil palm's environmental benefits are unclear.

Despite second-generation biofuels being better for biodiversity than first-generation biofuels on average, cotton-a second-generation crop-was the most damaging of all the crops analysed. Cotton farming typically involves heavy use of pesticides, which are known to have negative effects on the environment. The use of transgenic cotton varieties could alleviate some of the negative impacts (Abedullah et al. 2014), but our results indicate that cotton expansion for biofuel production would not be desirable. Using waste products from existing plantations could remain an option, as for many of the other crops analysed, although care would need to be given to ensure that this does not cause further land clearance. Also, removing crop residues from some plantations could have negative consequences for soil fertility and the diversity of fungi, beetles and birds (Wiens et al. 2011; Ranius et al. 2014), and there are technical challenges to overcome before it can become large-scale (Gadonneix et al. 2010). However, some second-generation crops can be grown on waste or marginal lands that are less suitable for the more profitable crops (Warren-Thomas et al. 2015; Conkling et al. 2017).

Perennial grass-reported as one of the more favourable biofuel crops for biodiversity (Robertson et al. 2011) — and rapeseed oil both had a positive effect on total abundance in our analyses. Perennial grass can provide habitat for migratory birds (Immerzeel et al. 2014) by mimicking natural grassland vegetation structure (Dornburg et al. 2010; Blank et al. 2016), while pollinators can benefit from the presence of flowering rapeseed oil crops (Holzschuh et al. 2012). However, we found a lower species richness in these croplands compared to primary vegetation, which could have a substantial effect on the ecosystem functioning and conservation value of the land.

Of all the biofuel crop categories in our models, rubber had the most similar species richness to primary vegetation. It also has favourable fuel properties compared to other crops, including soybean (Ikwuagwu et al. 2000). The rubber (and oil palm) sites in our analyses were all in Asia, a region where rubber is expanding rapidly; in 2012 it covered an area of land equivalent to $71 \%$ that of oil palm in Southeast Asia (WarrenThomas et al. 2015). We found a large variability in its effects on biodiversity, which reflects the wider literature. The thin canopy of rubber plantations allows light through, stimulating the growth of understory layers and providing habitat for other species (Peh et al. 2006). The oil-rich seeds may attract small mammals (Nakagawa et al. 2006) and increasing the distance between trees, retaining older trees and using agroforestry techniques can all help to increase the biodiversity value of rubber (Beukema et al. 2007; Mingxia et al. 2017). Our results agree to the extent that vertebrates were less affected by second-generation biofuel crops than invertebrates and plants. Contrastingly, other studies have found a reduced species richness in rubber plantations (Peh et al. 2006; Warren-Thomas et al. 2015; Mingxia et al. 2017). Further research is therefore needed to evaluate the reasons for the variation in response to rubber and to find which management techniques could be used to minimise its ecological impacts.

Asia and Central and South America showed the biggest effect sizes of biofuels, consistent with previous findings that there is geographic variability in the response of biodiversity in disturbed tropical forests and plantations (Gibson et al. 2011; Phillips et al. 2017). The regional differences we found can be partly attributed to variation in the crops grown in each region. For example, Central and South America had the most soybean sites and all oil palm sites were from Asia, both these crops being among the most detrimental first-generation crops. The Central and South America region also grows 
a lot of sugarcane for biofuel, but our data had no sugarcane sites, and therefore does not show the whole picture (Gadonneix et al. 2010). However, our results highlight the damaging nature of soybean croplands in the region. Regional differences could also be due to inherent differences in the resilience of the ecological communities, especially since most croplands in the tropics are created by replacing tropical forests, which are highly biodiverse ecosystems that are sensitive to disturbance (Phillips et al. 2017).

In North America, there was a large variability in the impacts of biofuels. Most sites had mixed crops or other oil crops. There were only three maize sites in our data for North America, yet maize is widely grown for biofuel in the region (Gadonneix et al. 2010); including more maize sites in our data would probably have led to a more evident negative response to first-generation biofuels. In Africa, all effects in biofuel croplands were negative, though first-generation sites were lacking. A more even and representative spread of crops across regions would have improved our models. In Europe, Oceania and North America, our results showed that second-generation biofuels were not as damaging to biodiversity, highlighting the potential of second-generation biofuels in these regions for creating less environmentally damaging biofuel. However, after rapeseed, soybean and palm oil are still likely to be the greatest sources of biodiesel (contributing 13\% each to total biofuel) in Europe, and maize the most important source of bioethanol (Valin et al. 2015). Similarly, in North America, the renewable fuel standard (RFS2) (2010) estimates that by 2022, $42 \%$ of renewables in transport fuels will still come from conventional biofuels, derived mainly from first-generation maize starch (Sorda et al. 2010).

When considering the overall responses of different taxa, the species richness of plants, invertebrates and vertebrates declined in both first- and second-generation biofuel sites, which is concerning given the projected expansion of the biofuel industry (International Energy Agency 2014; Núñez-Regueiro et al. 2020). For plants, the lower species richness coupled with the limited change in abundance could signal the overdominance of disturbance-tolerant species at the expense of more specialist species (Phillips et al. 2017), which could lead to biotic homogenisation and the absence of certain species. For example, a meta-analysis by Danielsen et al. (2009) found complete exclusion of epiphytic orchids and indigenous palms in oil palm plantations. Our results also showed that vertebrates were dramatically reduced in abundance in first-generation sites. Data limitations meant we did not test for variability within the vertebrate group. However, Núñez-Regueiro et al. (2020) found a strong increase in the abundance of mammals in ecosystems with biofuel crops, but a strong decrease in the abundance of birds. Additional analyses that consider the compositional similarity of sites with biofuel crops compared to other land-uses and breakdown biodiversity into different indices, species IUCN conservation status, trophic guild and native or alien status would provide useful information for conservation purposes in the future.

Although first-generation biofuels were more damaging to local biodiversity than second-generation biofuels, crop yield can influence which strategy might be best for conserving biodiversity. Lower-yielding second-generation biofuels generally produce less energy per unit area than first-generation biofuels, requiring more land clearance to generate the same amount of fuel, multiplying the negative impacts on biodiversity from habitat loss (Erb et al. 2012). For some of the biofuel crops having most biodiversity data in our analyses and a range of yields, Table 5 shows the crops' energy yields alongside their effects on local species richness and abundance, which can be combined to compare the cost (in terms of local biodiversity) per unit energy of different crops. For example, although firstgeneration oil palm's impact on local species richness is about 1.3 times greater than that 
of second-generation jatropha (Jatropha curcas), its biofuel yield is at least twice as great (Table 5), meaning that it has a lower impact on local species richness per unit of energy than does jatropha. Any such inferences must come with many caveats at present: we have shown that the effects of crops on biodiversity vary among regions and among taxa, and they are likely to also depend on other interacting factors that need further research, such as farming practices, surrounding habitat, and landscape characteristics; and biodiversity measures that incorporate species turnover are more sensitive to anthropogenic change than the measures we have used (Hillebrand et al. 2018). However, this kind of analysis can potentially help decide whether a land-sparing (more intensive, higher-yielding farming on a smaller land area) or a land-sharing (less intensive, lower-yielding farming on a greater land area) approach to future biofuel production would be better for biodiversity and therefore more sustainable (Barbier and Burgess 1997; Phalan et al. 2011).

Another relevant aspect that needs consideration in future decisions about biofuels and sustainable land-use is the change in biodiversity over time (Vellend et al. 2013; Dornelas et al. 2014). However, our approach of using space-for-time substitution gives relatively precise estimates of biodiversity change and the necessary time-series data are not currently available in the biofuel-biodiversity literature (De Palma et al. 2018). Lastly, different methods of analysis suitable for freshwater and marine habitats should be applied to include and contrast the impacts of other second- and third-generation biofuels that may have different effects on biodiversity, such as marine filter feeders and microalgae (Mallick et al. 2016; Hrůzová et al. 2020).

\section{Conclusions}

We have shown that biofuel crops have a negative effect on local species richness and total abundance, and that traditional first-generation biofuels are especially damaging, causing large declines in vertebrate abundance and plant species richness. Biofuels grown in Asia and Central and South America are the most detrimental, particularly oil palm and soybean, whereas in other regions there are smaller declines in biodiversity and some neutral and positive impacts. In order to minimise the destructive impacts of habitat loss on biodiversity, our results suggest that biofuel policies should not lead to further land clearance to

Table 5 Examples of biofuel crop yield and average local species richness and total abundance, compared to primary vegetation

\begin{tabular}{lllll}
\hline Biofuel crop & Biofuel generation & $\begin{array}{l}\text { Fuel yield } \\
(\text { gallons acre }\end{array}$ & $\begin{array}{l}\text { Average species richness } \\
\text { compared to primary } \\
\text { vegetation }(\%)\end{array}$ & $\begin{array}{l}\text { Average total abundance } \\
\text { compared to primary } \\
\text { vegetation }(\%)\end{array}$ \\
\hline Oil palm & First & $400-650$ & -31 & -64 \\
Soybean & First & $40-55$ & -46 & -71 \\
Maize & First & $18-20$ & -36 & -43 \\
Cotton & Second & $35-45$ & -49 & -86 \\
Jatropha & Second & $140-200$ & -24 & +22 \\
\hline
\end{tabular}

Biodiversity data are based on our analyses of data within the PREDICTS database as of March 2018. Biofuel data for jatropha are from the 'other oil crop' category in our analyses. Fuel yield data are based on potential fuel yields from Hoekman et al. (2012) 
grow biofuel crops, but should instead focus on other techniques, such as using degraded land or existing waste products. Biofuel policies that guide land-use decisions should be tailored to the local environment to meet both climate mitigation and biodiversity targets, with consideration given to the ecological systems in question, how they might be affected, and the yield they might produce.

Supplementary Information The online version contains supplementary material available at https://doi. org/10.1007/s 10531-021-02232-5.

Acknowledgements We are grateful to everyone who has contributed data to the PREDICTS project, and to the PREDICTS team for collating and curating the data, especially Emma Caton and Samantha Hill for curating the crop data. We are also grateful to the anonymous reviewers for their supportive and constructive feedback.

Authors' contributions Data analysis and writing the article: ST; guidance and editing: ADP, AP.

Funding This research was supported by NERC (NE/M014533/1) and the Prince Albert II of Monaco Foundation (Plants Under Pressure II).

Availability of data and material Data for this research comes from the PREDICTS database, part of the PREDICTS project. The biodiversity data are available from the data portal of the Natural History Museum, London (https://doi.org/10.5519/0066354), and the biofuel crop classification data are available in Online Resource 2 .

\section{Declarations}

Conflict of interest The authors declare that they have no conflict of interest.

Open Access This article is licensed under a Creative Commons Attribution 4.0 International License, which permits use, sharing, adaptation, distribution and reproduction in any medium or format, as long as you give appropriate credit to the original author(s) and the source, provide a link to the Creative Commons licence, and indicate if changes were made. The images or other third party material in this article are included in the article's Creative Commons licence, unless indicated otherwise in a credit line to the material. If material is not included in the article's Creative Commons licence and your intended use is not permitted by statutory regulation or exceeds the permitted use, you will need to obtain permission directly from the copyright holder. To view a copy of this licence, visit http://creativecommons.org/licenses/by/4.0/.

\section{References}

Abedullah KS, Qaim M (2014) Bt Cotton, pesticide use and environmental efficiency in Pakistan. J Agric Econ 66:66-86

Aratrakorn S, Thunhikorn S, Donald PF (2006) Changes in bird communities following conversion of lowland forest to oil palm and rubber plantations in southern Thailand. Bird Conserv Int 16:71-82

Araújo K, Mahajan D, Kerr R, da Silva M (2017) Global biofuels at the crossroads: an overview of technical, policy, and investment complexities in the sustainability of biofuel development. Agriculture $7: 32$

Arodudu O, Holmatov B, Voinov A (2020) Ecological impacts and limits of biomass use: a critical review. Clean Technol Environ Policy 22:1591-1611

Barbier EB, Burgess JC (1997) The economics of tropical forest land use options. Land Econ 73:174-195

Barnes AD, Jochum M, Mumme S, Haneda NF, Farajallah A, Widarto TH, Brose U (2014) Consequences of tropical land use for multitrophic biodiversity and ecosystem functioning. Nat Commun 5:5351

Bartoń K (2018) MuMIn: Multi-Model Inference. R package version 1.43.17. https://cran.r-project.org/web/ packages/MuMIn/index.html

Bates D, Maechler M, Bolker B, Walker S (2015) Fitting linear mixed-effects models using lme4. J Stat Softw 67:1-48 
Beringer T, Lucht W, Schaphoff S (2011) Bioenergy production potential of global biomass plantations under environmental and agricultural constraints. GCB Bioenergy 3:299-312

Beukema H, Danielsen F, Vincent G, Hardiwinoto S, van Andel J (2007) Plant and bird diversity in rubber agroforests in the lowlands of Sumatra, Indonesia. Agrofor Syst 70:217-242

Blank PJ, Williams CL, Sample DW, Meehan TD, Turner MG (2016) Alternative scenarios of bioenergy crop production in an agricultural landscape and implications for bird communities. Ecol Appl 26:42-54

Butchart SHM, Walpole M, Collen B et al (2010) Global biodiversity: indicators of recent declines. Science 328:1164-1168

Cerri CEP, You X, Cherubin MR, Moreira CS, Raucci GS, Castigioni BA, Alves PA, Cerri DGP, Mello FFC, Cerri CC (2017) Assessing the greenhouse gas emissions of Brazilian soybean biodiesel production. PLoS ONE 12:e0176948

Conkling TJ, Belant JL, DeVault TL, Martin JA (2017) Effects of crop type and harvest on nest survival and productivity of dickcissels in semi-natural grasslands. Agric Ecosyst Environ 240:224-232

Correa DF, Beyer HL, Possingham HP, Thomas-Hall SR, Schenk PM (2017) Biodiversity impacts of bioenergy production: microalgae vs. first generation biofuels. Renew Sustain Energy Rev 74:1131-1146

Danielsen F, Beukema H, Burgess ND, Parish F, Bruehl CA, Donald PF, Murdiyarso D, Phalan B, Reijnders L, Struebig M, Fitzherbert EB (2009) Biofuel plantations on forested lands: double jeopardy for biodiversity and climate. Conserv Biol 23:348-358

Dauber J, Jones MB, Stout JC (2010) The impact of biomass crop cultivation on temperate biodiversity. GCB Bioenergy 2:289-309

Dauber J, Miyake S (2016) To integrate or to segregate food crop and energy crop cultivation at the landscape scale? Perspectives on biodiversity conservation in agriculture in Europe. Energy Sustain Soc $6: 25$

De Palma A, Sanchez-Ortiz K, Martin PA, Chadwick A, Gilbert G, Bates AE, Börger L, Contu S, Hill S, Purvis A (2018) Challenges with inferring how land-use affects terrestrial biodiversity: study design, time, space and synthesis. Adv Ecol Res 58:163-199

Díaz S, Settele J, Brondízio ES et al (2019) Pervasive human-driven decline of life on Earth points to the need for transformative change. Science 366:eaax3100

Donald PF, Sanderson FJ, Burfield IJ, van Bommel FPJ (2006) Further evidence of continent-wide impacts of agricultural intensification on European farmland birds, 1990-2000. Agric Ecosyst Environ 116:189-196

Dornburg V, van Vuuren D, van de Ven G, Langeveld H, Meeusen M, Banse M, van Oorschot M, Ros J, van den Born GJ, Aiking H, Londo M, Mozaffarian H, Verweij P, Lysen E, Faaij A (2010) Bioenergy revisited: key factors in global potentials of bioenergy. Energy Environ Sci 3:258-267

Dornelas M, Gotelli NJ, McGill B, Shimadzu H, Moyes F, Sievers C, Magurran AE (2014) Assemblage time series reveal biodiversity change but not systematic loss. Science 344:296-299

Erb K, Haberl H, Plutzar C (2012) Dependency of global primary bioenergy crop potentials in 2050 on food systems, yields, biodiversity conservation and political stability. Energ Policy 47:260-269

Fahrig L, Baudry J, Brotons L, Burel FG, Crist TO, Fuller RJ, Sirami C, Siriwardena GM, Martin J (2011) Functional landscape heterogeneity and animal biodiversity in agricultural landscapes. Ecol Lett 14:101-112

Fargione JE, Plevin RJ, Hill JD (2010) The ecological impact of biofuels. Annu Rev Ecol Evol S 41:351-377

Fitzherbert EB, Struebig MJ, Morel A, Danielsen F, Bruehl CA, Donald PF, Phalan B (2008) How will oil palm expansion affect biodiversity? Trends Ecol Evol 23:538-545

Flather CH, Bevers M (2002) Patchy reaction-diffusion and population abundance: the relative importance of habitat amount and arrangement. Am Nat 159:40-56

Fletcher RJ Jr, Robertson BA, Evans J, Doran PJ, Alavalapati JRR, Schemske DW (2011) Biodiversity conservation in the era of biofuels: risks and opportunities. Front Ecol Environ 9:161-168

Fox J, Weisberg S (2011) An R companion to applied regression, 2nd edn. Sage, Thousand Oaks

Freudmann A, Mollik P, Tschapka M, Schulze CH (2015) Impacts of oil palm agriculture on phyllostomid bat assemblages. Biodivers Conserv 24:3583-3599

Godfray HCJ, Beddington JR, Crute IR, Haddad L, Lawrence D, Muir JF, Pretty J, Robinson S, Thomas SM, Toulmin C (2010) Food security: the challenge of feeding 9 billion people. Science 327:812-818

Gadonneix P, de Castro FB, de Medeiros NF et al (2010) Biofuels: Policies, Standards and Technologies. World Energy Council, London. https://www.worldenergy.org/assets/downloads/PUB_biofuels_Polic ies_Standards_and_Technologies_exec_sum_2010_WEC.pdf. Accessed April 2020

Gibson L, Lee TM, Koh LP, Brook BW, Gardner TA, Barlow J, Peres CA, Bradshaw CJA, Laurance WF, Lovejoy TE, Sodhi NS (2011) Primary forests are irreplaceable for sustaining tropical biodiversity. Nature 478:378-381 
Groom MJ, Gray EM, Townsend PA (2008) Biofuels and biodiversity: principles for creating better policies for biofuel production. Conserv Biol 22:602-609

Hadfield JD (2010) MCMC methods for multi-response generalized linear mixed models: the MCMCglmm R package. J Stat Soft 33:1-22

Haughton AJ, Bohan DA, Clark SJ, Mallott MD, Mallott V, Sage R, Karp A (2016) Dedicated biomass crops can enhance biodiversity in the arable landscape. GCB Bioenergy 8:1071-1081

Hill SL, Gonzalez R, Sanchez-Ortiz K, Caton E, Espinoza F, Newbold T, Tylianakis J, Scharlemann JP, De Palma A, Purvis A (2018) Worldwide impacts of past and projected future land-use change on local species richness and the Biodiversity Intactness Index. BioRxiv. https://doi.org/10.1101/311787

Hillebrand H, Blasius B, Borer ET et al (2018) Biodiversity change is uncoupled from species richness trends: consequences for conservation and monitoring. J Appl Ecol 55:169-184

Hoekman SK, Broch A, Robbins C, Ceniceros E, Natarajan M (2012) Review of biodiesel composition, properties, and specifications. Renew Sust Energ Rev 16:143-169

Holzschuh A, Dormann CF, Tscharntke T, Steffan-Dewenter I (2012) Mass-flowering crops enhance wild bee abundance. Oecologia 172:477-484

Hrůzová K, Matsakas L, Karnaouri A, Norén F, Rova U, Christakopoulos P (2020) Second-generation biofuel production from the marine filter feeder Ciona intestinalis. ACS Sustain Chem Eng 8:8373-8380

Hudson LN, Newbold T, Contu S et al (2014) The PREDICTS database: a global database of how local terrestrial biodiversity responds to human impacts. Ecol Evol 4:4701-4735

Hudson LN, Newbold T, Contu S et al (2017) The database of the PREDICTS (Projecting Responses of Ecological Diversity In Changing Terrestrial Systems) project. Ecol Evol 7:145-188

Ikwuagwu OE, Ononogbu IC, Njoku OU (2000) Production of biodiesel using rubber [Hevea brasiliensis (Kunth. Muell.)] seed oil. Ind Crop Prod 12:57-62

Immerzeel DJ, Verweij PA, van der Hilst F, Faaij APC (2014) Biodiversity impacts of bioenergy crop production: a state-of-the-art review. GCB Bioenergy 6:183-209

International Energy Agency (2014) World energy outlook 2014. International Energy Agency, Paris. https://doi.org/10.1787/weo-2014-en. Accessed April 2020

Kennedy CM, Lonsdorf E, Neel MC et al (2013) A global quantitative synthesis of local and landscape effects on wild bee pollinators in agroecosystems. Ecol Lett 16:584-599

Kline KL, Martinelli FS, Mayer AL, Medeiros R, Oliveira COF, Sparovek G, Walter A, Venier LA (2015) Bioenergy and biodiversity: key lessons from the Pan American Region. Environ Manage 56:1377-1396

Koh I, Lonsdorf EV, Williams NM, Brittain C, Isaacs R, Gibbs J, Ricketts TH (2016) Modeling the status, trends, and impacts of wild bee abundance in the United States. PNAS 113:140-145

Koh LP, Ghazoul J (2008) Biofuels, biodiversity, and people: understanding the conflicts and finding opportunities. Biol Conserv 141:2450-2460

Leite GB, Abdelaziz AEM, Hallenbeck PC (2013) Algal biofuels: challenges and opportunities. Bioresour Technol 145:134-141

Mallick N, Bagchi SK, Koley S, Singh AK (2016) Progress and challenges in microalgal biodiesel production. Front Microbiol 7:1019

Mathews JA (2007) Biofuels: what a Biopact between North and South could achieve. Energy Policy 35:3550-3570

Meijide A, de la Rua C, Guillaume T, Röll A, Hassler E, Stiegler C, Tjoa A, June T, Corre MD, Veldkamp E, Knohl A (2020) Measured greenhouse gas budgets challenge emission savings from palmoil biodiesel. Nat Commun 11:1089

Mingxia Z, Chang C, Ruichang Q (2017) Natural forest at landscape scale is most important for bird conservation in rubber plantation. Biol Conserv 210:243-252

Naeem S, Prager C, Weeks B et al (2016) Biodiversity as a multidimensional construct: a review, framework and case study of herbivory's impact on plant biodiversity. Proc R Soc B 283:20153005

Nakagawa M, Miguchi H, Nakashizuka T (2006) The effects of various forest uses on small mammal communities in Sarawak, Malaysia. For Ecol Manag 231:55-62

Newbold T, Hudson LN, Hill SLL et al (2015) Global effects of land use on local terrestrial biodiversity. Nature 520:45-50

Núñez-Regueiro MM, Fletcher RJ Jr, Siddiqui SF (2020) Effects of bioenergy on biodiversity arising from land-use change and crop type. Conserv Biol. https://doi.org/10.1111/cobi.13452

Peh KS-H, Sodhi NS, De Jong J, Sekercioglu CH, Yap CA-M, Lim SL-H (2006) Conservation value of degraded habitats for forest birds in southern Peninsular Malaysia. Divers Distrib 12:572-581

Phalan B, Onial M, Balmford A, Green RE (2011) Reconciling food production and biodiversity conservation: land sharing and land sparing compared. Science 333:1289-1291 
Phillips HRP, Newbold T, Purvis A (2017) Land-use effects on local biodiversity in tropical forests vary between continents. Biodivers Conserv 26:2251-2270

Poggio SL, Chaneton EJ, Ghersa CM (2013) The arable plant diversity of intensively managed farmland: effects of field position and crop type at local and landscape scales. Agric Ecosyst Environ 166:55-64

R Core Team (2017) R: a language and environment for statistical computing. R Foundation for Statistical Computing, Vienna. https://www.R-project.org

Ragauskas AJ, Williams CK, Davison BH, Britovsek G, Cairney J, Eckert CA, Frederick WJ Jr, Hallett JP, Leak DJ, Liotta CL, Mielenz JR, Murphy R, Templer R, Tschaplinski T (2006) The path forward for biofuels and biomaterials. Science 311:484-489

Ramankutty N, Evan AT, Monfreda C, Foley JA (2008) Farming the planet: 1. Geographic distribution of global agricultural lands in the year 2000. Glob Biogeochem Cycles 22:GB1003

Ranius T, Caruso A, Jonsell M, Juutinen A, Thor G, Rudolphi J (2014) Dead wood creation to compensate for habitat loss from intensive forestry. Biol Conserv 169:277-284

Raven PH, Wagner DL (2021) Agricultural intensification and climate change are rapidly decreasing insect biodiversity. PNAS 118: e2002548117

Robertson BA, Doran PJ, Loomis LR, Robertson JR, Schemske DW (2011) Perennial biomass feedstocks enhance avian diversity. GCB Bioenergy 3:235-246

Santini L, Belmaker J, Costello MJ et al (2016) Assessing the suitability of diversity metrics to detect biodiversity change. Biol Conserv 213:341-350

Szymanska-Chargot M, Chylinska M, Gdula K, Koziol A, Zdunek A (2017) Isolation and characterization of cellulose from different fruit and vegetable pomaces. Polym 9:495

Smith HG, Danhardt J, Lindstrom A, Rundlof M (2010) Consequences of organic farming and landscape heterogeneity for species richness and abundance of farmland birds. Oecologia 162:1071-1079

Sorda G, Banse M, Kemfert C (2010) An overview of biofuel policies across the world. Energ Policy 38:6977-6988

Thomas CD, Cameron A, Green RE et al (2004) Extinction risk from climate change. Nature 427:145-148

Thuiller W (2007) Biodiversity: climate change and the ecologist. Nature 448:550-552

Tilman D, Socolow R, Foley JA, Hill J, Larson E, Lynd L, Pacala S, Reilly J, Searchinger T, Somerville C, Williams R (2009) Beneficial biofuels-the food, energy, and environment trilemma. Science 325:270-271

Tittensor DP, Walpole M, Hill SLL et al (2014) A mid-term analysis of progress toward international biodiversity targets. Science 346:241-244

United Nations, Department of Economic and Social Affairs, Population Division (2019) World population prospects 2019: highlights. United Nations, New York

Valin A, Peters D, van den Berg M et al (2015) The land use change impact of biofuels consumed in the EU. Quantification of area and greenhouse gas impacts. European Commission, Utrecht, Netherlands. https://ec.europa.eu/energy/sites/ener/files/documents/Final\%20Report_GLOBIOM_publication.pdf. Accessed April 2020

Vanbeveren SPP, Ceulemans R (2019) Biodiversity in short-rotation coppice. Renew Sust Energ Rev 111:34-43

Vellend M, Baeten L, Myers-Smith IH, Elmendorf SC, Beausejour R, Brown CD, De Frenne P, Verheyen K, Wipf S (2013) Global meta-analysis reveals no net change in local-scale plant biodiversity over time. P Natl Acad Sci USA 110:19456-19459

Warren-Thomas E, Dolman P, Edwards D (2015) Increasing demand for natural rubber necessitates a robust sustainability initiative to mitigate impacts on Tropical biodiversity. Conserv Lett 8:230-241

Wiens J, Fargione J, Hill J (2011) Biofuels and biodiversity. Ecol Appl 21:1085-1095

Zuur AF, Ieno EN, Walker N, Saveliev AA, Smith GM (2009) Mixed effects models and extensions in ecology with R. Springer, New York

Publisher's Note Springer Nature remains neutral with regard to jurisdictional claims in published maps and institutional affiliations. 